\title{
NIIF y tributación: desafíos y oportunidades para las Administraciones tributarias
}

\author{
IFRS and Taxation: Challenges and \\ Opportunities for Tax Administrations
}

\section{IFRS e tributação: desafios e oportunidades para administrações tributárias}

Luis A. ChÁvez*

* Consultor y formador en NIIF® a nivel internacional. Miembro del SMEIG (Grupo Asesor del Consejo de Normas Internacionales de Contabilidad, IASB $\left.{ }^{\circledR}\right)$. Implementador de NIIF en empresas privadas. Consultor en NIIF para la Dirección de Impuestos y Aduanas Nacionales de Colombia (DIAN) y el Servicio de Administración de Rentas de Honduras (SAR). Correo-e: L_chavez86@hotmail.com ORCID ID: https://orcid.org/0000-0003-2230-7639 DoI: https://doi.org/10.18601/16926722.n17.04 


\section{Resumen}

Producto de la adopción de las Normas Internacionales de Información Financiera (NIIF) en Colombia, varios principios para la presentación y medición de los elementos contables han cambiado significativamente en relación con las prácticas que se venían aplicando antes. Esto vuelve necesario que los organismos de control tomen en consideración los diversos impactos. En el caso de las Administraciones Tributarias, es imperativo el análisis y la evaluación de los efectos que la aplicación de las NIIF pueden provocar en aquellos tributos en los que la base imponible se determina tomando como punto de partida la contabilidad -como lo es el impuesto a la renta. En consecuencia, es importante que la normativa tributaria de cada país sea debidamente reformada (o actualizada), para especificar los tratamientos fiscales de los nuevos registros contables por la aplicación de las NIIF. El presente documento recoge la experiencia del autor trabajando como consultor en NIIF para diversas Administraciones Tributarias en sus procesos de actualización y reformas fiscales; también su experiencia en el sector privado trabajando como implementador de las NIIF, y su visión como miembro del SMEIG (Grupo Asesor del Consejo de Normas Internacionales de Contabilidad - IASB). Con un formato amistoso, en un lenguaje claro y con varios ejemplos ilustrativos reales, este trabajo brinda un marco de referencia a las Administraciones Tributarias con la finalidad de afrontar con éxito los desafíos y oportunidades inherentes a este cambio de paradigma, en cumplimiento de las políticas fiscales y promoviendo la competitividad tributaria en los países.

Palabras clave: NIIF; IFRs; Contabilidad; Tributación; Impuestos.

\section{Abstract}

As a result of the adoption of the International Financial Reporting Standards (IFRS), several principles for the presentation and measurement of accounting elements have changed significantly in relation to the practices that had been previously applied. This makes it necessary for control agencies to take into account the various impacts. In the case of the Tax Administrations, it is imperative to analyze and evaluate the effects that the application of IFRS can cause in those taxes in which the tax base is determined based on the accounting starting point - as is the tax for rent. Consequently, it is important that the tax regulations of each country be duly amended (or updated), to specify the tax treatments of the new accounting records by the application of IFRS. This document gathers the author's experience working as a consultant in IFRS for various Tax Administrations in their tax update and reform processes; also his experience in the private sector working as an implementer of IFRS, and his vision as a member of the SMEIG (Advisory Group of the International Accounting Standards Board - IASB). With a friendly format, in a clear language and with several real illustrative examples, this work 
provides a frame of reference to the Tax Administrations in order to successfully face the challenges and opportunities inherent in this paradigm shift, in compliance with the policies fiscal and promoting tax competitiveness in countries.

Keywords: IFRS; IFRS; Accounting; Taxation; Taxes.

\section{Resumo}

Como resultado da adoção das Normas Internacionais de Relato Financeiro (IFRs), vários princípios para a apresentação e mensuração de elementos contábeis mudaram significativamente em relação às práticas anteriormente aplicadas. Isso torna necessário que as agências de controle levem em consideração os vários impactos. No caso das administrações tributárias, é imprescindível analisar e avaliar os efeitos que a aplicação do IFRS pode causar nos impostos em que a base tributária é determinada com base na contabilidade - assim como o imposto para alugar. Consequentemente, é importante que os regulamentos tributários de cada país sejam devidamente alterados (ou atualizados), para especificar os tratamentos tributários dos novos registros contábeis pela aplicação do IFRs. Este documento reúne a experiência do autor trabalhando como consultor em IFRS para várias administrações fiscais em seus processos de atualização e reforma tributária; também sua experiência no setor privado trabalhando como implementador de IFRS e sua visão como membro do SMEIG (Grupo Consultivo do International Accounting Standards Board -IASB). Com um formato amigável, em linguagem clara e com vários exemplos ilustrativos reais, este trabalho fornece um quadro de referência para as administrações tributárias, a fim de enfrentar com êxito os desafios e oportunidades inerentes a essa mudança de paradigma, em conformidade com as políticas fiscal e promovendo a competitividade tributária nos países.

Palavras-chave: IFRS; IFRS; Contabilidade; Tributação; Impostos.

\section{Introducción}

Por más de 30 años, en Latinoamérica los estados financieros de la mayoría de las empresas se venían preparando mediante la utilización de las reglas fiscales de cada país, y no necesariamente de principios financieros. Esta distorsión se ha denominado, a menudo, como tributarizar la contabilidad financiera, lo cual ha venido creando un híbrido que no es ni información financiera completamente, ni tampoco es información de carácter fiscal completamente, malográndose entonces el verdadero objetivo de los estados financieros: reflejar una imagen fiel de las transacciones para la adecuada toma de decisiones económicas sobre el suministro de recursos a una empresa.

Con la aplicación de las NIIF en América Latina, se está dando un mayor énfasis a los principios financieros para la preparación de estados financieros y, consecuentemente, se 
está presentando una tendencia a destributarizar la contabilidad financiera (es decir, dejar de aplicar las reglas fiscales para la preparación de estados financieros).

Sin embargo, en el ejercicio profesional del autor en estos años, mediante consultorías y capacitaciones a diversas empresas privadas en sus procesos de implementación de NIIF -si bien los empresarios e inversionistas, en primera instancia, reconocen las bondades de estas normas internacionales que tienen como objetivo reflejar la realidad económica de la empresa para una mejor toma de decisiones-, se ha podido comprobar que una gran limitante por la cual muchas empresas no logran una cabal aplicación de las mismas es la incertidumbre sobre los tratamientos tributarios de los nuevos tipos de ingresos y gastos, entre otros, que se deben contabilizar por la implementación de las NIIF, cuando la normativa fiscal de un país aún no ha sido debidamente reformada para considerar todos estos cambios contables - como es el caso del impuesto a la renta de sociedades, que toma como punto de partida lo reportado en los estados financieros.

Por consiguiente, si la preparación y presentación de dichos estados financieros evoluciona (por la aplicación de las NIIF), es imperativo que la normativa fiscal de un país también evolucione para considerar todos los nuevos casos y brindar certidumbre tributaria a las empresas e inversionistas, claro está, salvaguardando siempre los principios fundamentales de la tributación, como son por ejemplo: la capacidad contributiva y la neutralidad.

De esta forma, las empresas lograrán aplicar sin recelo todas las NIIF, apreciando entonces su realidad económica para una mejor toma de decisiones y obteniendo un mayor acceso a préstamos y a créditos a través de información financiera de alta calidad y, paralelamente, las empresas también lograrán cumplir correctamente con la normativa fiscal del país (puesto que la misma, de ser reformada, brindaría las debidas aclaraciones en el tratamiento fiscal de los nuevos tipos de registros contables).

Al ser considerado aquello por las Administraciones Tributarias, se les podrá brindar al inversionista y al empresario certidumbre sobre los efectos fiscales producto de la aplicación de las NIIF, promoviéndose la inversión local y extranjera, mejorando la competitividad tributaria de un país en la región latinoamericana. Este contexto económico, naturalmente, promoverá también un aumento en la recaudación fiscal.

A continuación pasaremos a abordar de manera más específica qué son las NIIF y cuáles son sus objetivos, para luego especificar los objetivos de los sistemas tributarios y sus normativas. Primero desarrollaremos cada tipo de normativa separadamente (financiera y tributaria), para después contrastarlas y analizar sus diferencias con el objetivo de brindar un marco de referencia a las Administraciones Tributarias en sus procesos de análisis de los efectos fiscales por la aplicación de las NIIF en los estados financieros de los contribuyentes. 


\section{Las Normas Internacionales de Información Financiera - NIIF}

Las Normas Internacionales de Información Financiera (NIIF, o también conocidas como IFRS, por sus siglas en inglés) son un conjunto de principios o estándares para la preparación de estados financieros con propósitos de información general. Las NIIF son emitidas por el Consejo de Normas Internacionales de Contabilidad (IASB, por sus siglas en inglés), un organismo con sede en Londres.

\section{A. Objetivo de los estados financieros con propósitos de información general}

Este producto, que se obtiene por la aplicación de las NIIF (que a veces en la práctica, denominamos de forma acortada como estados financieros), tiene como objetivo brindar información de la entidad sobre los siguientes aspectos que se muestran en la Figura 1.

Figura 1. INFORMACIÓN PROPORCIONADA EN LOS ESTADOS FINANCIEROS

Fuente: Elaboración propia.

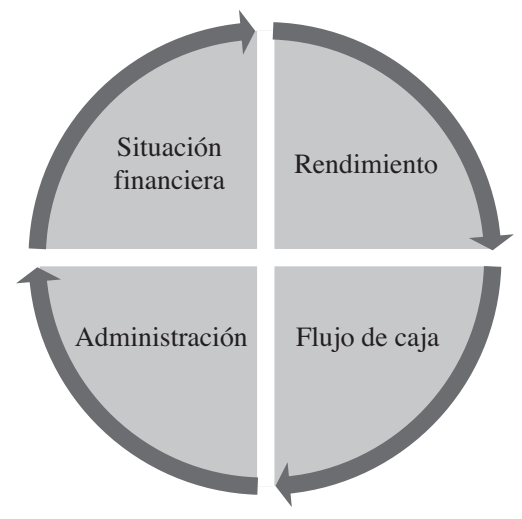

Los estados financieros tienen como propósito satisfacer las necesidades de información principalmente de inversores, prestamistas y otros acreedores existentes y potenciales para tomar decisiones sobre el suministro (o no) de recursos económicos a la entidad. Es decir, los estados financieros que se preparan bajo NIIF van destinados, en realidad, a proveedores de capital, principalmente para decisiones de financiamiento (de ahí su nombre: estados financieros).

De ahí que la información que se prepara y presenta bajo NIIF busque ser transparente y oportuna, mostrando una imagen fiel de las transacciones económicas, ya que va dirigida para quienes han puesto sus recursos económicos en la empresa (algún accionista, o algún comprador de bonos u obligaciones que ha emitido la empresa, por ejemplo), o para un proveedor de capital potencial (un inversor del extranjero que está interesado en invertir en nuestra empresa, o un banco al cual deseamos solicitar un préstamo, entre otros). Por 
tanto, las NIIF corresponden a un lenguaje financiero global entre las empresas que reportan y los diversos proveedores de capital (en otros palabras, vienen a ser un código de comunicación entre demandantes y oferentes de capital).

En definitiva, una empresa que no aplica cabalmente las NIIF, no podrá reflejar su verdadera situación económica y rendimiento, y estará en desventaja competitiva para la obtención de capital al no brindar información financiera transparente y de alta calidad.

\section{B. Principios básicos en las NIIF}

Entre los principios básicos contemplados en las NIIF para la preparación de los estados financieros, destacan los siguientes:

Devengo: también conocido como base de acumulación. Según este principio, los efectos de las transacciones y demás hechos se registran contablemente cuando ocurren, no necesariamente cuando se recibe o paga dinero. Los estados financieros preparados sobre la base de devengo informan a los usuarios no solo de las transacciones pasadas que significaron cobros o pagos de dinero, sino también de las obligaciones de pago en el futuro y de los recursos que representan efectivo a cobrar posteriormente. Por lo anterior, tales estados suministran el tipo de información acerca de las transacciones y otros hechos pasados que resultan más útiles a los usuarios al tomar decisiones económicas.

Empresa en marcha: los estados financieros se preparan normalmente sobre la base de que la empresa está en funcionamiento, y continuará sus actividades de operación dentro del futuro previsible. Por lo tanto, se asume que la empresa no tiene ni la intención ni la necesidad de liquidar o disminuir de forma importante el nivel de sus operaciones. El principio de empresa en marcha constituye el postulado fundamental de la información financiera que se prepara bajo NIIF. Si la entidad que reporta no cumpliese con el principio de empresa en marcha, los estados financieros tendrían que prepararse sobre una base diferente y, si así fuera, se revelará la base utilizada.

\section{Proceso de convergencia en América Latina}

El proceso de convergencia mundial hacia estos estándares genera nuevos desafíos y oportunidades para todos los tipos de entidades que implementen esta normativa internacional, y, por supuesto, a los organismos de control de estas entidades. Según datos del Consejo de Normas Internacionales de Contabilidad (IASB, por sus siglas en inglés), organismo emisor de las NIIF, actualmente más de 130 países exigen o permiten la aplicación de las NIIF Completas para la elaboración y presentación de los estados financieros de las compañías; y más de 80 países también han adoptado la NIIF para las PYMES. Este proceso de armonización de la información financiera definitivamente no ha sido ajeno a Latinoamérica. 


\section{¿QUÉ SON LAS NIIF COMPLETAS Y QUÉ TIPOS DE ENTIDADES DEBEN APLICARLAS?}

Las NIIF Completas comprenden un conjunto de estándares, a saber:

- Las Normas Internacionales de Contabilidad (NIC) y sus respectivas interpretaciones (SIC).

- Las Normas Internacionales de Información Financiera (NIIF) y sus respectivas interpretaciones (CINIIF).

El contenido de las NIIF Completas actualmente supera las 3.000 páginas y son aplicadas por empresas que tienen lo que se denomina la obligación pública de rendir cuentas. Una entidad tiene la obligación pública de rendir cuentas si:

- Sus instrumentos de deuda o de patrimonio se negocian en un mercado público o están en proceso de emitir estos instrumentos para negociarse en un mercado público (ya sea una bolsa de valores nacional o extranjera, o un mercado fuera de la bolsa de valores, incluyendo mercados locales o regionales); o

- una de sus principales actividades es mantener activos en calidad de fiduciaria para un amplio grupo de terceros (la mayoría de bancos, cooperativas de crédito, compañías de seguros, comisionistas e intermediarios de valores, fondos de inversión y bancos de inversión cumplirían este segundo criterio).

\section{¿QUÉ ES LA NIIF PARA LAS PYMES Y QUÉ TIPOS DE ENTIDADES DEBEN APLICARLA?}

La NIIF para las PYMES es un estándar basado en las NIIF Completas que debe ser aplicado de manera autónoma. La NIIF para las PYMES está subdividida en 35 secciones y comprende alrededor de 300 páginas. Las entidades pueden aplicar la NIIF para las PYMES, cuando:

- No tienen obligación pública de rendir cuentas y

- publican estados financieros con propósito de información general para usuarios externos.

Son ejemplos de usuarios externos los propietarios que no están implicados en la gestión del negocio, los acreedores actuales o potenciales y las agencias de calificación crediticia.

\section{Los sistemas tributarios y sus normativas}

El sistema tributario en cada país está conformado por un conjunto de tributos que ayudan, en primer lugar, a cumplir con los objetivos de naturaleza económica, por ejemplo: el empleo, el crecimiento y equilibrio económico. Pues se considera al sistema tributario como la principal corriente de ingresos que tiene un Estado para poder cubrir los gastos 
que demandan los ciudadanos, tales como: educación, vivienda, infraestructuras, salud, entre otros.

\section{A. Objetivos de los sistemas tributarios y sus normativas}

Los sistemas tributarios y sus normativas tienen como objetivos principales lograr una estabilidad económica, asignar apropiadamente los recursos, promover el crecimiento económico de un país, asegurar el empleo, brindar soberanía alimentaria, y que exista una justa distribución de las riquezas. En la actualidad, los tributos en cada país se encuentran regulados por los respectivos organismos de control, con el propósito de que, por medio de sus instrumentos y normativas, los contribuyentes tengan facilidad para cumplir con sus obligaciones tributarias. Las normativas tributarias corresponden a un conjunto de cuerpos legales que norman o regulan las actividades de los contribuyentes para el cumplimiento de sus tributos con el Estado. Tienen como objetivo permitir a las Administraciones Tributarias recaudar los recursos suficientes para financiar la inversión y el gasto público.

\section{B. Principios básicos de la tributación}

Los principios tributarios constituyen los elementos básicos que debe tener un tributo, entre los que se destacan los siguientes:

Legalidad: con este principio se indica la potestad exclusiva de un Estado para que un tributo sea establecido mediante ley, de manera que no es aplicable una imposición o un tributo sin que exista una ley que los haya establecido, es decir que no hay tributo sin que exista una ley previa.

Igualdad o Equidad: este principio requiere un trato equitativo a todos los sujetos pasivos, en igualdad de condiciones, sin que existan beneficios o gravámenes en función de raza, color, sexo, idioma, religión, filiación política, posición económica, entre otros. Este principio debemos entenderlo como igualdad para contribuyentes en condiciones similares.

Capacidad contributiva o Proporcionalidad: bajo este principio, los contribuyentes deben tributar de acuerdo a sus capacidades económicas. Es decir, que los sujetos del impuesto que mantengan una capacidad económica más alta, deberán realizar un pago mayor; lo contrario ocurre con un contribuyente que percibe ingresos más bajos, pues por ningún motivo, un tributo puede exceder la razonabilidad contributiva de las personas.

Neutralidad: este principio hace referencia a que la aplicación de los tributos no debe alterar el comportamiento económico de los contribuyentes, es decir, poca interferencia de la tributación en el funcionamiento del mercado.

Simplicidad: de acuerdo con este principio, un sistema tributario debe contar con una estructura técnica que le sea funcional. Que genere costos no elevados de cumplimiento por parte de los contribuyentes y de control por parte de la Administración Tributaria. 


\section{El impuesto a la renta}

Uno de los principales impuestos en las normativas tributarias es el impuesto a la renta (también conocido en algunos países como impuesto a las ganancias), el cual es aplicable sobre las rentas obtenidas por personas naturales o jurídicas sobre el que se aplica una tasa, ya sea esta fija o progresiva, y por este motivo, se considera un impuesto directo. De manera general, este impuesto es aplicable a todas actividades económicas realizadas por las personas naturales o jurídicas, según sea el caso, del cual se pueden deducir los descuentos, costos y gastos imputables a dichos ingresos, de tal manera que se logra identificar lo que llamamos base imponible -también conocida como utilidad gravable (o en su defecto, pérdida fiscal)- para el cálculo del impuesto a la renta.

Al momento de tener identificada la base imponible para el cálculo del impuesto, se aplica la tarifa correspondiente de acuerdo con la legislación vigente de cada país, obteniendo así el valor del impuesto causado. Este impuesto por lo general se lo calcula de manera anual, pues el contribuyente establece la base imponible con base en los ingresos gravables menos los costos y gastos deducibles que han sido obtenidos durante un año fiscal.

\section{NIIF y normativas tributarias: principales diferencias}

Nótese que la normativa financiera y la normativa tributaria, por sus naturalezas, persiguen objetivos distintos. Por una parte, las NIIF buscan reflejar la realidad económica de una empresa para satisfacer las necesidades de información de sus proveedores de capital $\mathrm{y}$, por otra parte, las normas tributarias buscan establecer reglas para salvaguardar los objetivos de recaudación fiscal de un Estado para financiar la inversión y el gasto público.

Es importante denotar que, en la práctica, la forma como se aplican las NIIF es a través de principios. Debido a que las NIIF son normas que se aplican en empresas con diferentes realidades económicas (e incluso de diferentes latitudes del mundo), dichas normas no pueden pretender reflejar una imagen fiel de todas las empresas (que tienen diferentes realidades y tipos de transacciones) a través de reglas fijas. Por ello, las NIIF contemplan la aplicación de principios, que requieren el uso del juicio profesional y de la mejor información disponible, para reflejar en los estados financieros la realidad económica de una empresa.

\section{EJEMPLO: ESTIMACIÓN DE LA VIDA ÚTIL Y GASTO POR DEPRECIACIÓN}

Un ejemplo de ello es la estimación de la vida útil de un elemento de propiedades, planta y equipo en una empresa. Las NIIF definen a la vida útil como el periodo durante el cual se espera que la entidad utilice el activo. Y la depreciación es la distribución sistemática del valor depreciable de un activo a lo largo de su vida útil. 
Consideremos a una empresa "A", que compra un vehículo y lo va a usar intensivamente en una zona rural. Utilizando el juicio profesional y la mejor información disponible, se estima una vida útil de 3 años para el vehículo. En consecuencia, el gasto por depreciación deberá calcularse en función de dicha vida útil, ya que representará el verdadero desgaste de dicho bien (es decir, la realidad económica de la empresa "A" con respecto a dicho vehículo).

En paralelo, consideremos a otra entidad, la empresa “B”, que adquiere el mismo vehículo, por el mismo valor y en la misma fecha. Sin embargo, esta empresa va a utilizar el vehículo eventualmente y en una zona urbana. Utilizando el juicio profesional y la mejor información disponible, se estima una vida útil de 7 años para el vehículo. Por consiguiente, el gasto por depreciación deberá calcularse en función de dicha vida útil, ya que representará el verdadero desgaste de dicho bien (es decir, la realidad económica de la empresa "B” en relación a su vehículo).

Es importante resaltar que aplicando las NIIF, pese a que las empresas " $\mathrm{A}$ " $\mathrm{y}$ " $\mathrm{B}$ ” adquirieron el mismo vehículo, por el mismo valor y en la misma fecha, sus tratamientos contables son diferentes, debido a la aplicación de principios que reflejan sus diferentes realidades económicas. Ahora bien, es importante destacar que, si bien las normas tributarias también se basan sobre principios fundamentales que describimos en la sección anterior, su forma de aplicación en la práctica es generalmente a través de reglas ${ }^{1}$.

Siguiendo el mismo ejemplo de las empresas "A" y "B", aunque para propósitos de la preparación y presentación de estados financieros, una empresa deprecia el vehículo en 3 años y la otra, en 7 años; para fines de la declaración del impuesto a la renta, la normativa tributaria de un país puede establecer, por ejemplo, que se permitirá como gasto deducible de impuestos (por concepto de depreciación) hasta el 20\% del costo del vehículo anualmente. Y esta regla se aplica en general a los diferentes contribuyentes para fines de la declaración del impuesto a la renta, indiferentemente del gasto por depreciación registrado en su estado de resultados por la aplicación de las NIIF $^{2}$.

Con lo anterior, no queremos denotar que un principio sea superior a una regla o viceversa, sino que, más bien, la aplicación de principios permite lograr cabalmente el objetivo propio de las NIIF; y que la aplicación de reglas, en el caso de las normativas tributarias, permite lograr también su objetivo.

1 Justamente para cumplir con el principio tributario de igualdad o equidad entre los contribuyentes.

2 Si los contribuyentes simplemente hubieran calculado y contabilizado un gasto por depreciación anual equivalente al 20\% del costo del vehículo amparándose directamente en la normativa tributaria, dicho enfoque habría sido erróneo, debido a que estarían tributarizando la contabilidad financiera (en lugar de haber aplicado los principios contemplados en las NIIF), y por tanto, no necesariamente estarían reflejando sus realidades económicas en los estados financieros. 


\section{Figura 2. DifERENCIAS ENTRE PRINCIPIOS Y REGLAS}
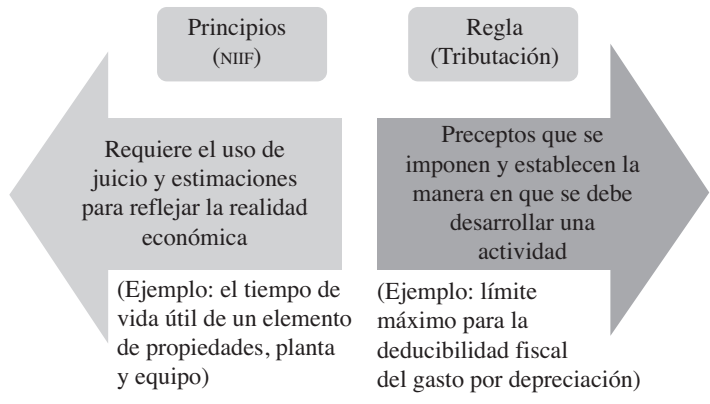

Fuente: Elaboración propia.

\section{Distorsión histórica en la preparación de estados financieros}

Siendo diferentes los objetivos de la normativa financiera y la normativa tributaria, lamentablemente por más de 3 décadas se ha presentado una distorsión histórica en la preparación y presentación de estados financieros en América Latina. Y ha sido el hecho de considerar a una normativa tributaria como si fuese la fuente o la base para la creación de políticas contables, y con estas, preparar y emitir los estados financieros. Esta concepción -que se muestra en la Figura 3- es errónea.

\section{Figura 3. Distorsión histórica EN la PREPARACión} de estados financieros en América Latina

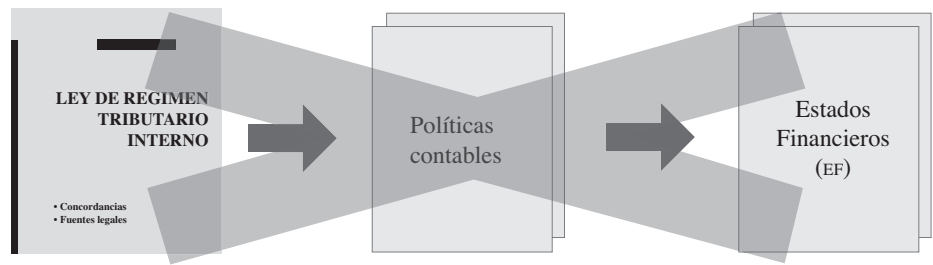

Fuente: Elaboración propia.

Como hemos destacado antes en este trabajo, las normativas tributarias no han sido creadas con el objetivo de brindar principios o directrices para la preparación de estados financieros (sino para salvaguardar la recaudación fiscal de un Estado). Esta distorsión se ha denominado a menudo como tributarizar la contabilidad financiera. Y tributarizar la contabilidad lo que produce es un híbrido, que no es completamente ni información financiera ni tampoco completamente información de carácter tributario; malográndose entonces el verdadero objetivo de los estados financieros, que es reflejar la realidad económica de la 
entidad para la toma de decisiones económicas de los proveedores de capital existentes y potenciales $^{3}$.
A continuación destacamos las principales causas de esta situación:

\section{- Una tradicional preponderancia de las reglas tributarias sobre la información financiera. \\ - El desconocimiento de los principios contables y técnicas por parte de los preparadores de estados financieros.}

- Incertidumbre de los efectos tributarios por la aplicación de las $\mathrm{NIIF}^{4}$.

3 Un ejemplo tradicional de aquello lo tenemos cuando al registrar en la contabilidad el gasto por cuentas incobrables o dudoso recaudo (deterioro del valor), las entidades han utilizado un porcentaje fijado en la normativa tributaria (dependiendo de la normativa tributaria de cada país, este porcentaje ha correspondido al $1 \%$ o $2 \%$, por ejemplo), en lugar de realizar un análisis crediticio de las cuentas por cobrar para registrar contablemente un deterioro en función de la realidad económica de la entidad (tal como lo requieren las NIIF). Si se realiza el análisis de conformidad con las NIIF, habrá casos de empresas en los que no se deba registrar deterioro alguno (o sea, ningún gasto por cuentas incobrables) en las cuentas por cobrar (porque puede ser que la entidad cuente con una cartera de crédito sana y de alta rotación).

Otro ejemplo clásico en las empresas lo tenemos cuando el gasto por depreciación ha sido registrado en la contabilidad siguiendo lineamientos tributarios (por ejemplo a través de un porcentaje o tasa establecida en la normativa tributaria). Esta ha sido muchas veces la situación de los edificios en algunos países, que han sido depreciados contablemente a una tasa del $5 \%$ anual sobre el costo (que equivale a una vida de 20 años), cuando en la realidad económica, la mayoría de los edificios tienen una vida útil ampliamente superior a los 20 años, y de conformidad con las NIF, dichos edificios más bien deben ser depreciados contablemente en función del verdadero tiempo que se espera que brinden beneficios económicos a la entidad (por consiguiente, la tasa de depreciación contable debería ser más baja que la fiscal).

4 Al trabajar en la implementación de las NIIF en empresas, si bien el empresario y los preparadores de estados financieros reconocen la utilidad de las NIIF para, por ejemplo, obtener un préstamo bancario, muchas empresas terminan siendo renuentes en aplicar ciertos principios contables debido a las contingencias tributarias que se pueden provocar. Por ejemplo, cuando se implementan las NIIF en una empresa agrícola, la norma internacional correspondiente requiere que el saldo contable de los activos biológicos (animales y plantas vivos utilizados en la actividad agrícola) sea actualizado periodo a periodo a su valor razonable menos costos de venta (lo que puede asimilarse como ajustar el saldo contable del activo biológico periódicamente a un valor corriente: de mercado). Como normalmente el activo biológico crece (transformación biológica), gana atributos físicos que lo hacen más apreciable en el mercado, y, por tanto, se incrementa su valor razonable. Por ello, el ajuste contable requeriría incrementar el saldo del activo biológico y, a su vez, reconocer un ingreso por este concepto en el estado de resultados. Producto de este requerimiento de las NIIF, el estado de situación financiera presentará un activo biológico a valores corrientes (o sea, valores de mercado, y no meramente costos históricos) y, además, el estado de resultados va a reflejar un rendimiento dentro del periodo que es producto de la actividad agrícola de la entidad. En este sentido, el empresario comprende y se siente a gusto de presentar estados financieros que reflejen dicha realidad económica. Como lo ha demostrado nuestra experiencia, aplicando las NIIF, algunas empresas agrícolas han obtenido mayor acceso a líneas de crédito, y en otros casos, sus proveedores del exterior han aumentado sus cupos de crédito -es ahí cuando la información financiera de alta calidad cumple su cometido: brindar un mayor acceso al capital, a través de información transparente, confiable y oportuna (esto se ha logrado cuando en el país se han hecho las reformas tributarias respectivas para aclarar que entonces estos ingresos, e incrementos en el saldo del activo biológico, no son objeto de impuesto a la renta). Sin embargo, si en un país la normativa tributaria no contempla de manera específica el tratamiento fiscal de dichos ingresos por la actualización del saldo del activo biológico a valores de mercado (ni el tratamiento fiscal del incremento en el saldo del activo -si existe algún impuesto que se calcula en función del valor de los activos), entonces los empresarios agrícolas y otros inversionistas pueden tornarse renuentes a la aplicación de las NIIF en la medición de sus activos biológicos, debido a que tienen incertidumbres tributarias en el caso de que se registren dichos incrementos en los activos y las respectivas ganancias contables, por lo cual, como también lo ha demostrado 
- Una mala interpretación de la premisa: En caso de divergencia entre las normas tributarias y las normas contables y financieras, prevalecerán las primeras ${ }^{5}$.

\section{Concepción correcta en la preparación de estados financieros}

Una correcta concepción en la preparación de estados financieros es considerar a una normativa financiera (por ejemplo: las NIIF Completas o la NIIF para las PYMES), como la fuente o la base para la creación de políticas contables en una entidad, y con base en dichas políticas contables, emitir los estados financieros con propósitos de información general, cuyo público objetivo corresponde a los inversores, prestamistas y otros acreedores existentes y potenciales de la entidad; en otras palabras, proveedores de capital.

Ahora bien, si en un país estos estados financieros también se utilizan para otros objetivos particulares, aquello viene a ser, más bien, un uso secundario o derivativo del objetivo principal que tiene la información financiera ${ }^{6}$.

Por ejemplo, el banco central de un país puede encontrar útil la información que publican las empresas en sus estados financieros para la elaboración de sus estadísticas por sectores económicos. Asimismo, una Administración Tributaria puede encontrar útil la información publicada en los estados financieros para el cálculo de un tributo, como es el caso del impuesto a la renta.

Si los estados financieros en un país se utilizan también como punto de partida o de referencia para el cálculo del impuesto a la renta ${ }^{7}$, entonces es a través de la herramienta conciliación tributaria, en donde -una vez ya obtenida la utilidad o pérdida contable producto de la aplicación cabal de las NIIF- se realizan ajustes extracontables para la declaración del impuesto a la renta (denominadas partidas conciliatorias) para convertir dicho resultado contable en una utilidad o pérdida para fines fiscales (denominada utilidad gravable o pérdida fiscal), y de esta manera, obtener el respectivo impuesto a la renta por pagar.

nuestra experiencia, las empresas en consecuencia se sesgan de la aplicación de las NIIF, y miden sus activos biológicos utilizando el costo histórico (es decir, acumulando en el saldo contable erogaciones históricas atribuibles al activo biológico, en lugar de una valoración de mercado), perdiendo de esta manera las empresas e inversionistas los beneficios derivados de la aplicación cabal de las NIIF.

5 Lamentablemente, ha existido una mala interpretación o sobredimensionamiento de esta premisa proveniente de las normativas tributarias. El alcance de esta premisa es únicamente el proceso de conciliación tributaria, es decir, cuando a la utilidad o pérdida contable (que se ha obtenido producto de la aplicación de las NIIF) se le realizan ajustes extracontables en la declaración del impuesto a la renta (partidas conciliatorias) de conformidad con la normativa tributaria para convertirla en una utilidad gravable o pérdida fiscal. Por lo anterior, el alcance de dicha premisa no debe transcender a la fase de preparación y presentación de estados financieros (en donde prima la normativa financiera).

6 Que es satisfacer las necesidades de información de los proveedores de capital (inversores, prestamistas y otros acreedores) existentes y potenciales de una entidad.

7 Como sucede en los países de Latinoamérica. 
Figura 4. Concepción CORRECTA EN LA PREPARACIÓN DE ESTADOS FINANCIEROS

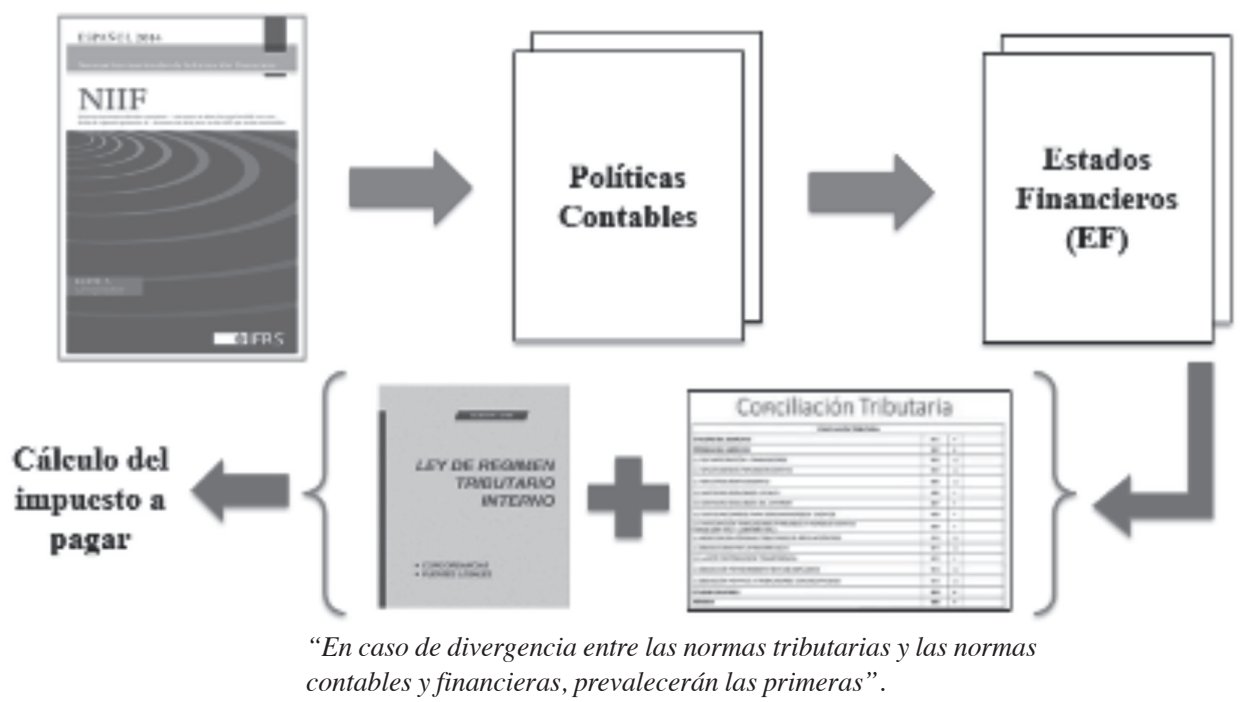

Fuente: Elaboración propia.

Una vez preparados los estados financieros de conformidad con las NIIF, nótese en la Figura 4 que es a través de una segunda fase (es decir, ya cuando se está calculando la utilidad gravable o pérdida fiscal mediante la conciliación tributaria) en donde se aplica a rigor lo que establezca la normativa tributaria de un país y se calcula el correspondiente impuesto a pagar.

Es en esta segunda fase en donde se aplica la premisa: En caso de divergencia entre las normas tributarias y las normas contables y financieras, prevalecerán las primeras, debido a que en esta fase ya no estamos preparando estados financieros, sino calculando la base para el cálculo de un tributo, en donde prima la normativa tributaria.

Nótese entonces que las NIIF y la normativa tributaria sí pueden coexistir. Los roles de ambas normativas no se superponen; más bien, se complementan: el accionar de la normativa tributaria empieza una vez que ha terminado el accionar de la normativa financiera.

\section{A. La conciliación tributaria}

La conciliación tributaria es una herramienta complementaria que sirve para transformar a los resultados contables en resultados fiscales. En otras palabras, la conciliación tributaria es de naturaleza extracontable. Al utilizar el término extracontable en el presente documento nos referimos a que son ajustes (aumentos o disminuciones) que se realizan sobre el resultado contable bajo NIIF, pero dichos ajustes no se registran en los cuentas contables 
como tales, sino que es a través de un procedimiento aparte en donde se reexpresa la utilidad o pérdida contable, para convertirla en una utilidad gravable o pérdida fiscal. Sobre este resultado se aplica la tasa fiscal correspondiente para obtener así un impuesto a la renta causado.

\section{EJEMPLO: GASTO CONTABLE NO DEDUCIBLE PARA FINES DEL IMPUESTO A LA RENTA}

Por ejemplo, consideremos a un contribuyente que ha obtenido una ganancia contable (ingresos contables menos costos y gastos contables) de $\$ 9.000$ en su estado de resultados (producto de la aplicación de las NIIF). Dentro de los gastos contables se encuentra registrada una multa por un valor de $\$ 1.000$ que -aunque es un gasto para fines contables- es considerado como un gasto no deducible de impuesto a la renta en la normativa tributaria del país.

Existiendo esta diferencia entre lo contable y lo fiscal, es a través del proceso de conciliación tributaria que resolvemos esta divergencia. Como dicho gasto se ha restado al momento de calcular la ganancia contable, para anular dicho efecto deberemos sumarlo en la conciliación tributaria, a manera de una partida conciliatoria (extracontable) ${ }^{8}$. En otras palabras, hemos restituido dicho gasto por la multa $(\$ 1.000)$ a la ganancia contable (\$9.000), para obtener así una utilidad gravable ${ }^{9}(\$ 10.000)$.

Cuando a dicha utilidad gravable se la multiplica por la tasa fiscal aplicable, entonces se obtiene el impuesto a la renta causado. La Figura 5, que se muestra a continuación, resume el ejemplo anterior y el uso de la conciliación tributaria ${ }^{10}$ :

Figura 5. Conciliación tributaria y Cálculo del impuesto a la Renta

\begin{tabular}{|l|r|}
\hline Ganancia (pérdida) contable & 9.000 \\
\hline Conciliación tributaria & \\
\hline (+) Multa & 1.000 \\
\hline (=) Utilidad gravable (pérdida fiscal & 10.000 \\
\hline Tarifa de impuesto a la renta & $22 \%$ \\
\hline Impuesto causado & 2.220 \\
\hline
\end{tabular}

Fuente: Elaboración propia.

8 Sobre el ejemplo, asumamos que el resto de costos y gastos son deducibles del impuesto a la renta, y que todos los ingresos son gravados del impuesto a la renta. Si, en otro caso, hubiesen existido ingresos contables que no son gravados para fines del impuesto a la renta, estos valores tendrían que haber sido restados en la conciliación tributaria.

9 A la utilidad gravable también se la conoce como base imponible o ganancia fiscal.

10 Se ha asumido en este ejemplo una tarifa aplicable de impuesto a la renta del $22 \%$. 


\section{B. Los estados financieros preparados bajo NIF como un punto de partida para la determinación de una base imponible}

Puesto que los estados financieros preparados bajo NIIF constituyen una imagen fiel de la situación financiera y el rendimiento de un contribuyente, la utilidad contable se puede considerar como un punto de partida (ajustando dicha utilidad contable con ciertas limitaciones y excepciones) para la determinación de la base imponible para el cálculo del impuesto a la renta.

Sin embargo, las normativas financiera y tributaria persiguen objetivos distintos, por lo cual es importante que las Administraciones Tributarias lleven a cabo cuidadosamente procesos de análisis y reformas en sus normativas tributarias, incorporando nuevos conceptos, terminologías y técnicas procedentes de la normativa financiera, considerando ciertas excepciones y limitaciones sobre dichos conceptos y técnicas, en cumplimiento de la política fiscal y garantizando el cumplimiento de los principios fundamentales de la tributación, tales como: legalidad, igualdad, capacidad contributiva, neutralidad y simplicidad.

Hemos destacado anteriormente que el medio para lograr la coexistencia y cabal aplicación tanto de la normativa financiera como de la normativa tributaria es la conciliación tributaria. Adicional a ello, es también necesario indicar que cuando se cumple cabalmente con ambas normativas, naturalmente deben contabilizarse los denominados impuestos diferidos. En otras palabras, por el momento diremos que el registro contable de los impuestos diferidos nace del cumplimiento tanto de la normativa financiera como de la normativa tributaria.

\section{Figura 6. Registro de impuestos difERIDOS PROdUCTO de LA APLiCACIÓN} DE LAS NIIF Y DEL CUMPLIMIENTO SIMULTÁNEO DE LA NORMATIVA TRIBUTARIA
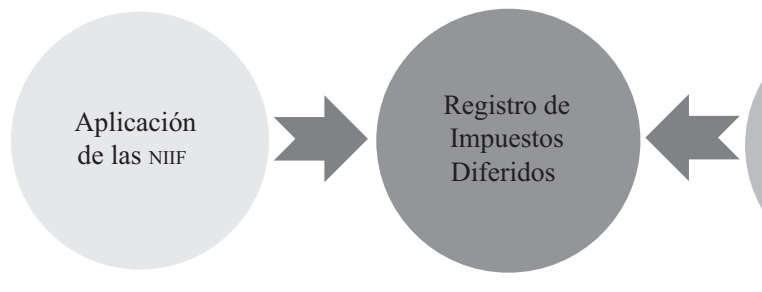

Aplicación

de las

normas tributarias

Fuente: Elaboración propia.

A continuación, explicaremos más a detalle este concepto de 'impuestos diferidos' que hemos introducido. 


\section{Cambiando de paradigma: los impuestos diferidos conciliando las diferencias}

De acuerdo con las NIIF, cuando se registran contablemente los efectos del impuesto a la renta, este debe reflejar en los estados financieros las consecuencias fiscales actuales y futuras. Las consecuencias fiscales actuales quedan reflejadas cuando contabilizamos el impuesto a la renta por pagar de cada año (también conocido como impuesto corriente). Por otro lado, las consecuencias fiscales futuras quedan reflejadas mediante el registro de los impuestos diferidos. Los impuestos diferidos pueden ser de dos tipos:

- Activos por impuestos diferidos.

- Pasivos por impuestos diferidos.

\section{A. Activos por impuestos diferidos}

En términos generales, un activo por impuesto diferido representa una deducción tributaria en ejercicios fiscales futuros (mediante la conciliación tributaria), producto de la recuperación de un activo o la liquidación de un pasivo ${ }^{11}$.

Para explicar la funcionalidad del activo por impuesto diferido y cómo el mismo permite el cabal cumplimiento de las NIIF y de la normativa tributaria simultáneamente, consideremos un ejemplo práctico.

\section{EJEMPLO: PÉRDIDA POR DETERIORO DEL VALOR DE INVENTARIO}

Al 31 de diciembre de 2018, una partida de inventarios con un saldo en libros de $\$ 100.000$ se ha deteriorado en su valor. En cumplimiento de las NIIF, el contribuyente ha reducido el saldo en libros de dicho inventario a $\$ 70.000$, reconociendo una pérdida en el estado de resultados por $\$ 30.000$. Durante el 2019, el contribuyente vende dicho inventario en $\$ 70.000$.

En el 2018:

En aplicación de las NIIF (técnica contable), el contribuyente debe deteriorar dicho inventario por un valor de $\$ 30.000$ en el 2018 , de la siguiente manera:

\begin{tabular}{|c|c|c|}
\hline \multicolumn{1}{|c|}{ Cuentas contables } & Débito & Crédito \\
\hline Pérdida por deterioro del valor de inventarios & 30.000 & \\
\hline Deterioro acumulado del valor de inventarios & & 30.000 \\
\hline
\end{tabular}

11 También podemos considerar que el activo por impuesto diferido simboliza un crédito tributario que será recuperable (a través de la conciliación tributaria) en ejercicios fiscales subsiguientes. 
En donde la cuenta Pérdida por deterioro del valor de inventarios es una cuenta de gastos en el estado de resultados; y la cuenta Deterioro acumulado del valor de inventarios es una cuenta correctora de activo (cuenta de valuación). De esta manera, los usuarios de los estados financieros obtienen información confiable y oportuna, útil para la toma de decisiones económicas.

Ahora bien, si la normativa tributaria del país establece, por ejemplo, que este gasto contable (correspondiente a un deterioro parcial del valor del inventario) no será deducible para fines del impuesto a la renta, sino hasta el momento en que dicho inventario deteriorado sea vendido o auto-consumido, entonces dicho gasto deberá ser ajustado (sumado) en la conciliación tributaria del ejercicio fiscal $2018^{[12]}$.

Para el ejercicio fiscal 2018, si bien es cierto que la empresa ha deteriorado contablemente el valor del inventario de conformidad con las NIIF (técnica contable), aún no ha vendido ni autoconsumido el mismo. Por tal motivo, el contribuyente deberá considerar dicha pérdida, por el momento, como gasto no deducible en la conciliación tributaria con la expectativa de que pueda ser deducible más adelante cuando se cumplan las condiciones requeridas en la normativa tributaria.

En consecuencia, dentro de la conciliación tributaria, la pérdida por deterioro del valor de $\$ 30.000$ deberá ser considerada como un aumento de la base imponible (a manera de gasto no deducible del impuesto a la renta) en la declaración del ejercicio fiscal 2018:

\begin{tabular}{|l|r|}
\hline Ganancia contable & XXXX \\
\hline Conciliación tributaria & \\
\hline (+) Pérdida por deterioro del valor & 30.000 \\
\hline
\end{tabular}

Como se genera una diferencia temporaria entre lo contable y lo fiscal, puesto que, para fines tributarios, se espera deducir los $\$ 30.000$ más adelante (cuando se recupere el activo, es decir, cuando se venda o auto-consuma el inventario) ${ }^{13}$, el contribuyente deberá contabilizar el respectivo activo por impuesto diferido (la tasa fiscal que se considera vigente para el ejercicio fiscal en el que se reversará la diferencia temporaria es del 22\%). El activo por impuesto diferido es de $\$ 6.600$ (es decir: $\$ 30.000 * 22 \%$ ).

\begin{tabular}{|l|l|l|}
\hline \multicolumn{1}{|c|}{ Cuentas contables } & Débito & Crédito \\
\hline Activo por impuesto diferido & 6.600 & \\
\hline Impuesto a la renta & & 6.600 \\
\hline
\end{tabular}

12 Esto resulta procedente cuando la normativa tributaria del país aclara específicamente el tratamiento fiscal de las pérdidas por deterioro parcial del valor del inventario. Sin embargo, cuando en un país no se ha reformado (o aclarado) la normativa tributaria considerando el tratamiento fiscal de estos conceptos, entonces surge la incertidumbre fiscal, y ante la falta de claridad, en la práctica algunos contribuyentes lo han considerado como gasto deducible del impuesto a la renta en el momento que se registra contablemente, disminuyendo la base imponible.

13 En las NIIF, esta diferencia recibe el nombre de diferencia temporaria deducible. 
Este Activo por impuesto diferido registrado al 31 de diciembre de 2018, representa el derecho a deducción (mediante conciliación tributaria) que tiene el contribuyente en ejercicios fiscales futuros para su cálculo del Impuesto a la renta. El registro contable de este activo se realiza contra el Impuesto a la renta, que es la cuenta del estado de resultados que debe reflejar no solo las consecuencias fiscales actuales, sino también, las consecuencias fiscales futuras (es decir, los efectos de los impuestos diferidos $)^{14}$.

Aunque ya hemos contabilizado de manera intuitiva el activo por impuesto diferido, este se calcula formalmente utilizando una metodología denominada método del pasivo basado en el balance contemplada en las NIIF. Esta metodología básicamente compara el valor en libros de los diferentes activos y pasivos de una empresa (que deben estar valorados aplicando la norma internacional correspondiente) contra su respectiva base fiscal (que es el valor atribuido para fines tributarios a dichos activos y pasivos). De existir alguna diferencia entre el valor en libros y la base fiscal, se generará una diferencia (denominada diferencia temporaria), que, al multiplicarse por la tasa fiscal que se espera que esté vigente en el futuro (cuando se reversen las diferencias), generará un impuesto diferido (que puede ser un activo o pasivo por impuesto diferido).

Dicho lo anterior, procedemos a calcular el respectivo activo por impuesto diferido de manera ortodoxa utilizando el método del pasivo basado en el balance:

\begin{tabular}{|c|c|c|c|}
\hline Valor en libros & Base Fiscal $^{15}$ & Diferencia temporaria & Impuesto diferido \\
\hline 70.000 & 100.000 & $(30.000)$ & $(6.600)$ \\
\hline
\end{tabular}

En el 2019:

En el ejercicio fiscal siguiente, año 2019, cuando el contribuyente vende su inventario deteriorado, deberá realizar los siguientes registros contables (de acuerdo con los antecedentes del ejemplo, el inventario fue vendido efectivamente en \$70.000):

\begin{tabular}{|l|l|l|}
\hline \multicolumn{1}{|c|}{ Cuentas contables } & \multicolumn{1}{c|}{ Débito } & Crédito \\
\hline Efectivo & 70.000 & \\
\hline Ingreso por venta de bienes & & 70.000 \\
\hline
\end{tabular}

14 Nuestro objetivo principal en esta sección es desarrollar en el lector una noción o intuición sobre el concepto de impuesto diferido, explicando cuál es el razonamiento detrás de este registro contable, debido a que, en la práctica, para un apropiado dominio y aplicación de los impuestos diferidos, resulta bastante contundente -en primera instancia- entender el aspecto lógico que subyace en la contabilización de estos conceptos.

15 De acuerdo con las NIIF, la base fiscal de un activo es el importe que será deducible a efectos fiscales de los beneficios económicos imponibles que obtenga la entidad en el futuro, cuando recupere el importe en libros de dicho activo. Si tales beneficios económicos no fueran imponibles, la base fiscal del activo será igual a su importe en libros. En nuestro ejemplo, para fines fiscales, todo el costo de $\$ 100.000$ del inventario (es decir, la parte deteriorada de $\$ 30.000$, más el costo remanente de $\$ 70.000$ ) podrá ser deducible más adelante, en el momento que se produzca la venta o autoconsumo. 


\begin{tabular}{|l|l|c|}
\hline \multicolumn{1}{|c|}{ Cuentas contables } & Débito & Crédito \\
\hline Costo de ventas & 70.000 & \\
\hline Deterioro acumulado del valor de inventarios & 30.000 & \\
\hline Inventarios & & 100.000 \\
\hline
\end{tabular}

De tal manera que el inventario deteriorado ha sido dado de baja por completo (incluyendo la cuenta correctora de activo), y se reconoce el respectivo ingreso y costo de ventas ${ }^{16}$.

Nótese que en el año 2019 no ha existido una afectación neta por esta transacción en el estado de resultados, ya que los $\$ 70.000$ contabilizados como ingresos por la venta se compensan automáticamente con los $\$ 70.000$ reconocidos como costo de ventas.

No obstante, el contribuyente ha cumplido ahora con las condiciones para deducirse los \$30.000 que registró contablemente en el ejercicio fiscal anterior y que reconoció como no deducible de impuesto a la renta en dicho ejercicio anterior, ¿cómo puede hacer deducible entonces ahora en el 2019 este concepto?

Recordemos que en el ejercicio fiscal 2018, el contribuyente dejó registrado un activo por impuesto diferido, que representa la posible deducibilidad en el futuro de un gasto contable que anteriormente se reconoció para fines fiscales como no deducible de impuesto a la renta.

Entonces, para poder recuperar dicha deducción fiscal, el contribuyente deberá reversar (recuperar) el activo por impuesto diferido en el ejercicio fiscal 2019, de la siguiente forma:

\begin{tabular}{|l|l|l|}
\hline \multicolumn{1}{|c|}{ Cuentas contables } & \multicolumn{1}{c|}{ Débito } & \multicolumn{1}{c|}{ Crédito } \\
\hline Impuesto a la renta & 6.600 & \\
\hline Activo por impuesto diferido & & 6.600 \\
\hline
\end{tabular}

En paralelo, deberá reconocer su respectiva deducción fiscal dentro de la conciliación tributaria, así:

\begin{tabular}{|l|r|}
\hline Ganancia contable & XXXX \\
\hline Conciliación tributaria & \\
\hline (-) Pérdida por deterioro del valor & 30.000 \\
\hline
\end{tabular}

Es importante destacar que ahora el efecto en la conciliación tributaria es negativo (deducción), y por tanto, disminuirá la base imponible (utilidad gravable) en una cuantía de

16 Las NIIF no incluyen especificaciones sobre el registro contable de las ventas de los inventarios deteriorados. En la práctica, el uso de una cuenta correctora (para la acumulación del deterioro del inventario en el estado de situación financiera) es opcional. No obstante, se recomienda su uso. Otra alternativa podría ser disminuir directamente la cuenta de costo histórico del inventario. En cualquiera de los casos, cuando el inventario deteriorado sea vendido, su saldo deberá darse de baja teniendo en cuenta su deterioro del valor (al igual que la baja de una cuenta por cobrar deteriorada). En consecuencia, en el costo de ventas (estado de resultados) se reconocerá el efecto neto (costo menos deterioro acumulado) por la venta del inventario que fue previamente deteriorado. 
$\$ 30.000$ en el ejercicio fiscal 2019, generando un ahorro efectivo de impuestos de $\$ 6.600$ (una vez aplicada la tarifa de impuesto del $22 \%$ ).

De esta manera, la diferencia temporaria quedaría reversada y el activo por impuesto diferido quedaría recuperado (a través de la deducción en la conciliación tributaria del ejercicio fiscal 2019).

\section{B. Principales causales del registro de activos por impuestos diferidos}

Hemos denotado que los impuestos diferidos surgen por las diferencias existentes en el tratamiento financiero y tributario de una misma transacción económica.

En el caso particular de los activos por impuestos diferidos, estos pueden ser generados principalmente por el hecho de que en la aplicación de las NIIF existen ciertos gastos (o pérdidas) contables que son producto de estimaciones basándose en principios (uso del juicio profesional y la mejor información disponible), como lo fue el ejemplo reciente sobre la pérdida por deterioro del valor del inventario. Debido a que es una estimación (aunque puede ser exacta o muy buena), una normativa tributaria podría considerar dicho gasto o pérdida como no deducible del impuesto a la renta hasta el momento -y en la medida de- que dichas estimaciones se terminen volviendo realidad (es decir, cuando los hechos sean consumados).

Otra situación que puede generar un activo por impuesto diferido (o sea, un derecho a deducción fiscal futura) es el hecho de que bajo NIIF puede existir el registro contable de un gasto (o una pérdida) sin que necesariamente exista un ingreso contable relacionado. Por ejemplo, cuando una entidad se encuentra en su etapa pre-operativa, los desembolsos correspondientes a esta etapa por el comienzo de la actividad (o de la entidad) deben ser contabilizados directamente como gastos en el estado de resultados. En consecuencia, durante esta etapa pre-operativa, la entidad puede presentar pérdidas en su estado de resultados al cierre del ejercicio. Por lo anterior, las NIIF no necesariamente trabajan con un principio de asociación ingreso-gasto.

Sin embargo, por la experiencia obtenida trabajando con Administraciones Tributarias, en las normativas fiscales nacionales generalmente existe una regla básica que establece que un gasto es deducible para fines del impuesto a la renta siempre que se asocie a un ingreso gravado. Es decir, la doctrina tributaria generalmente contempla un principio de asociación ingreso-gasto para la determinación de la base imponible del impuesto a la renta.

Consecuentemente, una normativa tributaria podría establecer que los gastos pre-operativos serán deducibles para fines del impuesto a la renta en el momento en que la entidad comience a generar ingresos gravados (renta gravada), lo cual puede suceder en un ejercicio fiscal posterior al que se registraron los gastos pre-operativos contablemente.

En este sentido, la entidad deberá considerar como no deducibles (en la conciliación tributaria) aquellos gastos pre-operativos en el ejercicio fiscal en el que aún no ha generado renta gravada (registrando simultáneamente un activo por impuesto diferido); y luego, recuperar su deducción (vía la conciliación tributaria) en el ejercicio fiscal siguiente en el cual se genere la renta gravada (reversando entonces el activo por impuesto diferido). 


\section{Figura 7. Principales Causales de activos Por impuestos diferidos}

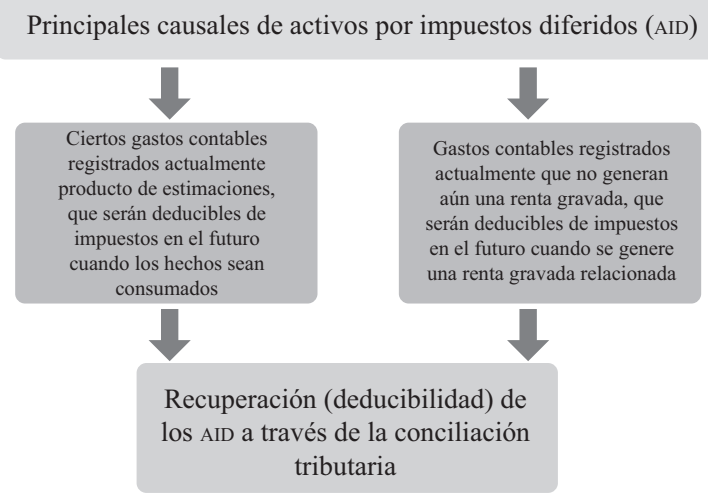

Fuente: Elaboración propia.

Para finalizar esta sección correspondiente a los activos por impuestos diferidos, es importante indicar que el propósito de la misma ha sido destacar las principales causales de la existencia de activos por impuestos diferidos en la práctica, denotando las naturales diferencias entre lo contable y lo fiscal y cómo se concilian dichas diferencias, a manera de un marco de referencia u orientación para las Administraciones Tributarias. Sin embargo, podrían existir eventualmente otras causales que generen el registro contable de activos por impuestos diferidos ${ }^{17}$.

\section{Pasivos por impuestos diferidos}

En términos generales, un pasivo por impuesto diferido, por lo contrario, representa una obligación tributaria para ejercicios fiscales futuros (mediante la conciliación tributaria), producto de la recuperación de un activo o la liquidación de un pasivo.

Para explicar la funcionalidad del pasivo por impuesto diferido y cómo el mismo permite el cabal cumplimiento de las NIIF y de la normativa tributaria de un país, consideremos también un ejemplo práctico.

\section{EJEMPLO: MEdición DE LOS ACTIVOS BIOLÓGICOS}

Durante el ejercicio fiscal 2018, un contribuyente registra inicialmente un activo biológico $^{18}$ por un valor de $\$ 1.000$. Al 31 de diciembre de 2018, el contribuyente ha incurrido

17 Por ejemplo, también pueden generarse activos por impuestos diferidos por pérdidas fiscales y créditos tributarios de periodos anteriores, entre otros.

18 Un activo biológico corresponde a un animal vivo o planta viva que se utilizan en una actividad agrícola. Por ejemplo, el ganado constituye un activo biológico para una empresa agropecuaria. Asimismo, la teca constituye 
en costos de producción directamente relacionados con la transformación biológica del activo, por un valor total de \$5.000. A la misma fecha, el valor razonable menos los costos de venta del activo biológico es de $\$ 10.000^{[19]}$. El contribuyente vende el activo biológico al iniciar el año 2019 por un valor de \$10.000. Durante 2019, el contribuyente no incurrió en costo de producción alguno para la transformación biológica del activo.

En el 2018:

En la adquisición del activo biológico, el contribuyente del ejemplo deberá realizar el siguiente asiento contable:

\begin{tabular}{|l|l|l|}
\hline \multicolumn{1}{|c|}{ Cuentas contables } & \multicolumn{1}{c|}{ Débito } & Crédito \\
\hline Activos biológicos & 1.000 & \\
\hline Efectivo & & 1.000 \\
\hline
\end{tabular}

Para la contabilización de los costos de producción incurridos en el ejercicio fiscal 2018, el contribuyente podría reconocerlos como gastos en el estado de resultados en el ejercicio que se incurren, de la siguiente manera ${ }^{20}$ :

\begin{tabular}{|l|l|l|}
\hline \multicolumn{1}{|c|}{ Cuentas contables } & Débito & \multicolumn{1}{c|}{ Crédito } \\
\hline Costos de producción & 5.000 & \\
\hline Efectivo / Cuentas por pagar / Otras cuentas & & 5.000 \\
\hline
\end{tabular}

Por la actualización del saldo contable del activo biológico desde $\$ 1.000$ hasta $\$ 10.000$ al 31 de diciembre de 2018, el contribuyente puede registrar una ganancia en el estado de resultados por medición al valor razonable menos los costos de venta, por un valor de $\$ 9.000$, como se muestra a continuación:

\begin{tabular}{|l|l|l|}
\hline \multicolumn{1}{|c|}{ Cuentas contables } & \multicolumn{1}{c|}{ Débito } & \multicolumn{1}{c|}{ Crédito } \\
\hline Activos biológicos & 9.000 & \\
\hline $\begin{array}{l}\text { Ganancias por medición a valor razonable } \\
\text { menos costos de venta }\end{array}$ & & 9.000 \\
\hline
\end{tabular}

un activo biológico para una empresa dedicada a la silvicultura.

19 En términos generales, aquello puede asimilarse como tener que actualizar el saldo contable del activo biológico a su valor de mercado (es decir, a un valor corriente) al cierre del ejercicio fiscal.

20 Las NIIF no incluyen especificaciones sobre el tratamiento contable de los gastos posteriores en la actividad agrícola (por ejemplo, costos de alimentación, servicios de veterinaria, sembrado, desmalezado, riego, fertilización, cosecha y faena). Por consiguiente, las entidades podrían optar por capitalizar (activar) dichos costos. En la práctica, muchas entidades reconocen estos costos de producción como gasto (en el estado de resultados) en el periodo en que se incurre en ellos. Para el ejemplo que estamos desarrollando aplicaremos este último enfoque. 
Por consiguiente, se generará una utilidad de operación de \$4.000 (\$9.000 - \$5.000) en el estado de resultados. ¿Qué tratamiento tributario debe darse a la ganancia contable registrada y sus costos de producción asociados?

Si la normativa tributaria del país establece, por ejemplo, que esta ganancia contable (correspondiente a la medición del activo biológico a su valor razonable menos costos de venta) no será gravada para fines del impuesto a la renta, sino hasta el momento en que dicho activo biológico sea vendido, entonces dicha ganancia deberá ser ajustada (restada) en la conciliación tributaria del ejercicio fiscal $2018^{[21]}$. Por consistencia, si este tipo de ganancias no es objeto de impuesto a la renta (mientras el activo no se haya vendido), los costos de producción asociados tampoco serán deducibles de impuesto a la renta sino hasta el momento en que dicho activo biológico sea vendido.

Para el ejercicio fiscal 2018, si bien es cierto que la empresa ha contabilizado ganancias y costos asociados por la medición del activo biológico de conformidad con las NIIF (técnica contable), no ha vendido el mismo (o dispuesto de este). Por tal motivo, el contribuyente deberá considerar estas ganancias contables como ingresos no objeto de impuesto a la renta por el momento, y sus costos de producción asociados como costos atribuibles a ingresos no objeto de impuesto a la renta (es decir, no deducibles), ambos en la conciliación tributaria, con la expectativa de que puedan ser gravados y deducibles respectivamente más adelante cuando se cumplan las condiciones establecidas en la normativa tributaria.

Consencuentemente, dentro de la conciliación tributaria del ejercicio fiscal 2018, la ganancia por medición del activo biológico al valor razonable menos costos de venta de \$9.000 deberá ser considerada como una disminución de la base imponible (como ingreso

21 Esto resulta procedente cuando la normativa tributaria del país aclara específicamente el tratamiento fiscal de las ganancias producto de la medición de los activos biológicos a su valor razonable menos costos de venta. Sin embargo, cuando en un país no se ha reformado (o aclarado) la normativa tributaria considerando el tratamiento fiscal de estos conceptos, entonces existe la incertidumbre fiscal, y ante la falta de claridad, algunos contribuyentes por conservadurismo han declarado las ganancias por medición a valor razonable menos costos de venta como ingresos gravados del impuesto a la renta, rompiéndose el principio de capacidad contributiva y perjudicando la liquidez de la empresa (debido a que el contribuyente aún no ha vendido su activo biológico, dichos ingresos contables se han generado, simplemente, producto de la actualización al valor de mercado del activo biológico, es decir, es un ingreso contable por valoración financiera, mas no por una venta real). Por la experiencia obtenida trabajando con organismos de control en el sector público, esto ha generado en la práctica que en ciertos países algunos sectores agrícolas se vean perjudicados significativamente, afectando su capital de trabajo y prefiriendo medir el activo biológico al modelo de costo histórico (en lugar de valores de mercado). Recordemos que los sistemas tributarios y sus normativas tienen como objetivos principales lograr una estabilidad económica y promover el crecimiento económico de un país. Adicionalmente, por el principio de neutralidad estos nuevos tipos de registros contables no deben generar ni un menor-ni un mayor-pago del impuesto a la renta en relación con los montos de impuesto que normalmente se tenía contemplado antes de la aplicación de las NIIF en cada país, ya que de lo contrario, alteraría el comportamiento económico de los contribuyentes y el funcionamiento del mercado. Al generarse distorsiones y no brindarse una certidumbre fiscal por la aplicación de las NIIF, por experiencias cercanas trabajando como consultor en el sector privado, esto ha afectado las decisiones de los inversionistas al evaluar en qué país de la región invertir su capital (sintiéndose más atraídos por aquellos países en donde la normativa tributaria brinda todas las claridades necesarias ante los nuevos tipos de registros contables producto de la aplicación de las NIIF - producto de la estabilidad jurídica). 
no objeto de impuesto a la renta), y, a su vez, los costos de producción asociados por un total de $\$ 5.000$ representarán un aumento de la base imponible (a manera de gasto no deducible), como se muestra a continuación:

\begin{tabular}{|l|r|}
\hline Ganancia contable & XXXX \\
\hline Conciliación tributaria & $(9.000)$ \\
\hline $\begin{array}{l}\text { (-) Ganancia por medición a valor razonable } \\
\text { menos costos de venta }\end{array}$ & 5.000 \\
\hline (+) Costos de producción & \\
\hline
\end{tabular}

Nótese que el efecto neto en las partidas conciliatorias por la medición del activo biológico es una utilidad no objeto de impuesto a la renta por $\$ 4.000$ (que representa, en esencia, la utilidad en operación que el contribuyente no tributa ahora, pero tendrá que tributar en el futuro cuando se cumplan las condiciones establecidas en la normativa tributaria (o sea, cuando venda el activo biológico).

Nótese que se genera una diferencia temporaria entre lo contable y lo fiscal, por la utilidad de $\$ 4.000$ que se presenta contablemente en el 2018 pero que tributará en un ejercicio fiscal futuro ${ }^{22}$. Por lo anterior, el contribuyente deberá contabilizar el respectivo pasivo por impuesto diferido (la tasa fiscal que se considera vigente para el ejercicio fiscal en el que se reversará la diferencia temporaria es del 22\%). El pasivo por impuesto diferido es de $\$ 880$ (es decir: $\$ 4.000 * 22 \%$ ).

\begin{tabular}{|l|l|l|}
\hline \multicolumn{1}{|c|}{ Cuentas contables } & \multicolumn{1}{c|}{ Débito } & \multicolumn{1}{c|}{ Crédito } \\
\hline Impuesto a la renta & 880 & \\
\hline Pasivo por impuesto diferido & & 880 \\
\hline
\end{tabular}

Si bien ya calculamos el pasivo por impuesto diferido de manera intuitiva, también podemos hacerlo de manera ortodoxa utilizando el 'método del pasivo basado en el balance':

\begin{tabular}{|l|l|l|l|}
\hline \multicolumn{1}{|c|}{ Valor en libros } & \multicolumn{1}{|c|}{ Base fiscal $^{23}$} & Diferencia temporaria & \multicolumn{1}{c|}{ Impuesto diferido } \\
\hline 10.000 & 6.000 & 4.000 & 880 \\
\hline
\end{tabular}

22 Esta diferencia recibe el nombre de diferencia temporaria imponible.

23 De conformidad con las NIIF, la base fiscal de un activo es el importe que será deducible a efectos fiscales de los beneficios económicos imponibles que obtenga la entidad en el futuro, cuando recupere el importe en libros de dicho activo. Si tales beneficios económicos no fueran imponibles, la base fiscal del activo será igual a su importe en libros. En nuestro ejemplo, para fines fiscales, el valor que será deducible de impuesto a la renta en relación con el activo biológico serán los costos incurridos en el mismo (en este caso: el valor pagado para adquirir el activo biológico de \$1.000 más los costos de producción incurridos durante el ejercicio fiscal 2018, de $\$ 5.000)$. 
Este Pasivo por impuesto diferido registrado al 31 de diciembre de 2018 representa un efecto imponible para el contribuyente en ejercicios fiscales futuros para su cálculo del Impuesto a la renta (mediante conciliación tributaria). El registro contable de este pasivo se realiza contra el Impuesto a la renta, que es la cuenta del estado de resultados que debe reflejar no solo las consecuencias fiscales actuales, sino también las consecuencias fiscales futuras (es decir, los efectos de los impuestos diferidos).

\section{En el 2019:}

En el ejercicio fiscal siguiente, en el año 2019, cuando el contribuyente vende su activo biológico, deberá realizar los siguientes registros contables (de acuerdo a los antecedentes del ejemplo, el activo biológico fue vendido efectivamente en \$10.000):

\begin{tabular}{|l|l|l|}
\hline \multicolumn{1}{|c|}{ Cuentas contables } & \multicolumn{1}{c|}{ Débito } & \multicolumn{1}{c|}{ Crédito } \\
\hline Efectivo & 10.000 & \\
\hline Activos biológicos & & 10.000 \\
\hline
\end{tabular}

De tal manera que el activo biológico ha sido dado de baja por completo (coincidentemente, se vendió a un monto igual a su última valoración en la contabilidad), y se reconoce la respectiva percepción del efectivo ${ }^{24}$. De acuerdo con los antecedentes, el contribuyente no incurrió en costos de producción asociados con este activo biológico en 2019, por lo que no procede ningún registro contable.

Nótese que en el 2019 no ha existido una afectación neta por esta transacción en el estado de resultados, ya que los $\$ 4.000$ que se generan como utilidad de operación $(\$ 10.000$ menos los costos incurridos por el activo biológico de $\$ 6.000$ - incluido el precio de adquisición), fueron reconocidos contablemente (pero no tributados) en el ejercicio fiscal 2018. Entonces, ¿cómo puede hacer el contribuyente ahora imponible (tributable) este concepto?

Recordemos que en el ejercicio fiscal 2018 el contribuyente dejó registrado un pasivo por impuesto diferido, que representa la posible imposición en el futuro de una utilidad de operación (ingresos brutos menos costos de producción) que anteriormente se reconoció para fines fiscales como no objeto de impuesto a la renta. Entonces, para poder liquidar dicha obligación fiscal, el contribuyente deberá reversar el pasivo por impuesto diferido ahora en el ejercicio fiscal 2019, como se explica en el siguiente cuadro.

24 Las NIIF no incluyen especificaciones sobre el registro contable de las ventas de los activos biológicos. En el Material de Formación sobre la NIIF para las PYMES elaborado por el personal de educación de la Fundación IFRS (el organismo que supervisa las actividades del Consejo de Normas Internacionales de Contabilidad -IASB), se puede apreciar que en las ventas de los activos biológicos se acredita la cuenta de activo y se registra directamente la contraprestación recibida (en nuestro ejemplo: efectivo). Si existe alguna diferencia entre el monto de la contraprestación recibida y el saldo del activo biológico que se acredita, dicha diferencia deberá reconocerse directamente en resultados. 


\begin{tabular}{|l|l|l|}
\hline \multicolumn{1}{|c|}{ Cuentas contables } & \multicolumn{1}{c|}{ Débito } & \multicolumn{1}{c|}{ Crédito } \\
\hline Pasivo por impuesto diferido & 880 & \\
\hline Impuesto a la renta & & 880 \\
\hline
\end{tabular}

En paralelo, deberá reconocer el respectivo efecto de gravamen (o imposición) dentro de la conciliación tributaria del 2019, así:

\begin{tabular}{|l|r|}
\hline Ganancia contable & XXXX \\
\hline Conciliación tributaria & \\
\hline $\begin{array}{l}\text { (+) Ganancia por medición a valor razonable } \\
\text { menos costos de venta }\end{array}$ & 9.000 \\
\hline (-) Costos de producción & $(5.000)$ \\
\hline
\end{tabular}

Nótese que, en la conciliación tributaria, el efecto del ingreso bruto por la medición del activo biológico ahora es positivo (imposición), y el costo asociado es negativo (deducción) y, por tanto, en términos netos, aumentará la base imponible (utilidad gravable) en una cuantía de $\$ 4.000$ en el ejercicio fiscal 2019, generando un pago efectivo de impuestos (aplicando la tarifa del 22\%) de $\$ 880$ en dicho año, que se relaciona con la utilidad de operación (ingresos menos costos) que no fue imponible en el ejercicio fiscal anterior.

De esta manera, la diferencia temporaria quedaría reversada y el pasivo por impuesto diferido quedaría liquidado (a través de la imposición en la conciliación tributaria del ejercicio fiscal 2019).

\section{Principales causales del registro de pasivos por impuestos diferidos}

Hemos indicado que los impuestos diferidos surgen por las diferencias existentes en el tratamiento financiero y tributario de una misma transacción económica.

En el caso particular de los pasivos por impuestos diferidos, estos pueden ser generados principalmente por el hecho de que en la aplicación de las NIIF existen ciertos ingresos (o ganancias) contables que no constituyen una renta para fines tributarios, como fue el caso del ejemplo reciente sobre la medición de los activos biológicos a su valor razonable menos costos de venta. Estos ingresos contables podrían ser gravados para fines tributarios en otro periodo fiscal; por ejemplo, cuando el activo relacionado sea vendido. Esto generará una diferencia temporaria imponible (es decir, un valor a sumar posteriormente en la conciliación tributaria), y en consecuencia, un pasivo por impuesto diferido.

Otra situación que puede generar una diferencia temporaria imponible (o sea, valores a sumar posteriormente en la conciliación tributaria) y, en consecuencia, pasivos por impuestos diferidos, se debe a ciertos activos que para fines contables han sido revaluados (incrementando su saldo en libros por encima del costo histórico) pero que, para fines fiscales, la normativa tributaria podría considerar que dicho valor incrementado en el activo (producto de la revaluación) no será deducible para el cálculo de la base imponible del 
impuesto a la renta (aunque dicho activo genere ingresos gravados). En este tipo de activos, el valor contable será superior a su base fiscal (es decir, el valor contable será mayor a los valores deducibles futuros para fines fiscales), y por tanto, se generará una diferencia temporaria, que corresponde a los valores no deducibles en el futuro cuando el activo sea recuperado (por ejemplo, cuando se vaya depreciando). Debido a que el efecto fiscal futuro corresponde a valores que serán sumados posteriormente en la conciliación tributaria, el tipo de diferencia que se produce es de carácter imponible, por lo cual, se generan pasivos por impuestos diferidos.

\section{Figura 8. Principales causales de Pasivos por impuestos diferidos}

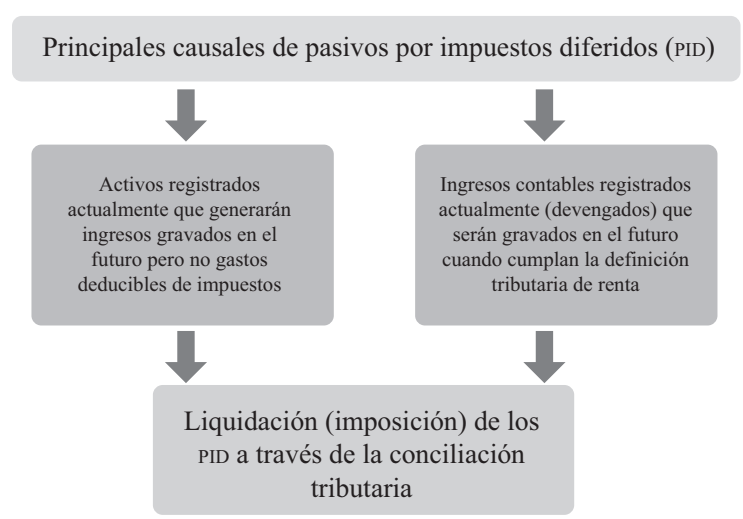

Fuente: Elaboración propia.

Para finalizar esta sección sobre pasivos por impuestos diferidos, es importante indicar que el propósito de la misma ha sido destacar las principales causales de la existencia de pasivos por impuestos diferidos en la práctica, denotando las naturales diferencias entre lo contable y lo fiscal y cómo se concilian dichas diferencias, a manera de un marco de referencia u orientación para las Administraciones Tributarias. Sin embargo, podrían existir eventualmente otras causales que generen el registro contable de pasivos por impuestos diferidos.

\section{E. Una reflexión}

En este punto, el lector se podrá preguntar por qué anteriormente en América Latina generalmente no se habían registrado en la contabilidad los activos o pasivos por impuestos diferidos. Como podrá notar, el registro contable de los impuestos diferidos obedece al cumplimiento simultáneo de la normativa financiera y la normativa tributaria. Sin embargo, antes de la aplicación de las NIIF en cada país de la región, la contabilidad había estado tradicionalmente tributarizada, por lo cual, prácticamente no existían diferencias temporarias entre lo contable y lo fiscal. 


\section{Diferencia entre ingreso contable y renta}

Como ya habrá notado el lector, no todos los ingresos contables que se registran por la aplicación de las NIIF constituyen renta desde un punto de vista tributario, como se muestra en la Figura 9.

Figura 9. Ingresos Contables (DEVEngados) y RENTa (Tributación)

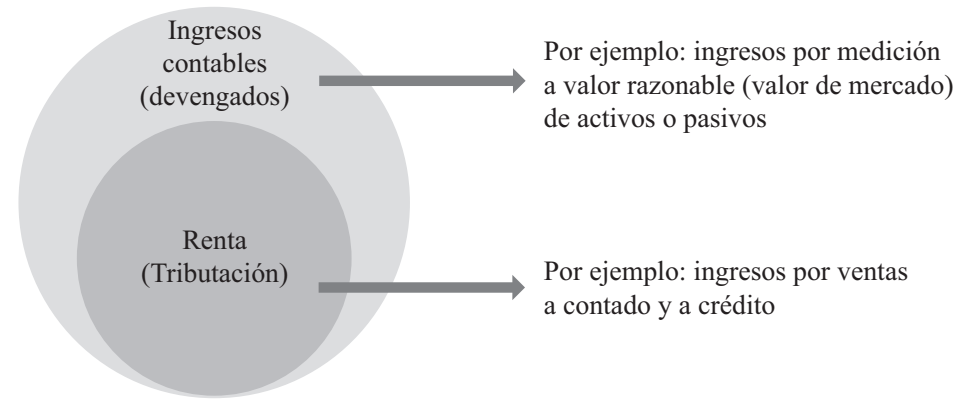

Fuente: Elaboración propia.

Por lo anterior, es importante que las Administraciones Tributarias tengan presente que al momento de analizar y regular el tratamiento fiscal de un ingreso contable, el análisis tradicional que evalúa directamente si dicho ingreso es renta gravada o exenta ya no sería procedente en la actualidad con la aplicación de las NIIF.

\section{Figura 10. Análisis tributario tradicional del ingReso CONTABLE}

Fuente: Elaboración propia.

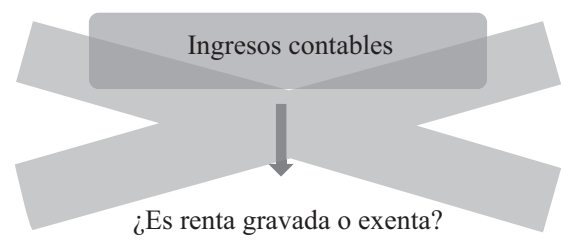

Por tanto, se alienta a las Administraciones Tributarias a regular el tratamiento fiscal del ingreso contable evaluando en primera instancia si dicho ingreso cumple con la definición tributaria de renta.

Si no cumple, entonces el ingreso no está bajo el alcance del impuesto (y, por tanto, se trata de un ingreso no objeto de impuesto a la renta); y, si la cumple, entonces se procede a analizar si es renta gravada o exenta, como se muestra en la Figura 11. 
Figura 11. Un nUevo ENFoQue de anÁlisis tributario del ingreso Contable

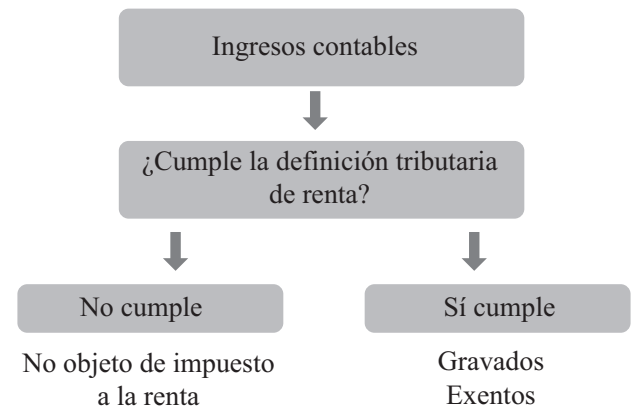

Fuente: Elaboración propia.

Asimismo, es necesario regular el tratamiento fiscal de los costos y gastos que surgen por la aplicación de las NIIF asociados propiamente a rentas, y asociados a ingresos no objeto de impuesto a la renta.

\section{Figura 12. Gastos Contables (DEVEngados) y gaStos atribuibles a RENTAS}

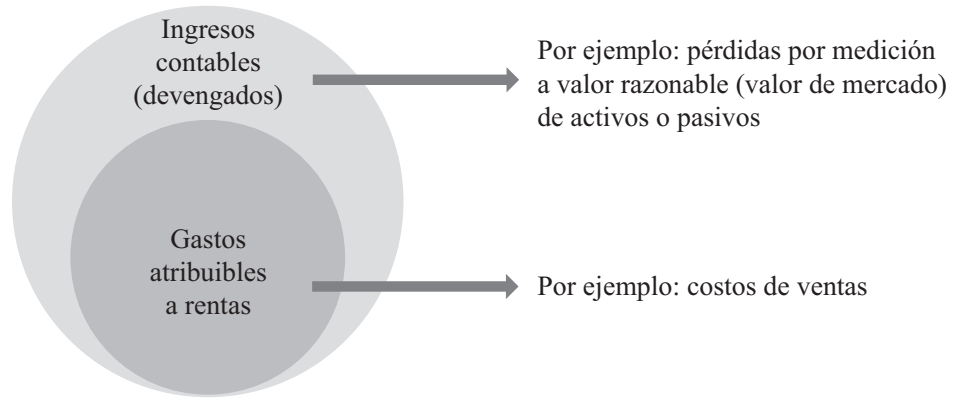

Fuente: Elaboración propia.

\section{Conclusiones}

De lo expuesto en el presente trabajo, podemos arribar a las siguientes conclusiones:

- Aunque la normativa financiera y la normativa tributaria persiguen objetivos distintos, sí pueden coexistir, mediante la conciliación tributaria y el registro de impuestos diferidos.

- Los roles de ambas normativas no se superponen; más bien, se complementan: el accionar de la normativa tributaria empieza una vez que ha terminado el accionar de la normativa financiera. 
- Con la correcta aplicación de las NIIF y de la normativa tributaria se logra un objetivo dual:

- Cuando las entidades preparan y presentan información financiera de alta calidad, se pueden tomar mejores decisiones económicas y tienen un mayor acceso al capital.

- El cálculo del impuesto a la renta toma como punto de partida el resultado contable, y en la medida en que las NIIF hayan sido aplicadas correctamente y que la normativa fiscal del país brinde la claridad necesaria para ajustar dicho resultado contable, los resultados tributarios generados serán también los apropiados.

La profesión contable y tributaria, las empresas y los organismos de control enfrentan en la actualidad oportunidades y desafíos relevantes por la aplicación de las NIIF. Somos afortunados de vivir en esta época de importantes cambios en nuestros países. Con este cambio de paradigma que se está presentado en Latinoamérica, las presentes y nuevas generaciones de contribuyentes podrán comprender claramente las diferencias entre las normativas financieras y tributarias, cuáles son sus objetivos, y de qué manera deben ser conciliadas sus diferencias.

Si bien la tributarización de la contabilidad financiera ha estado arraigada por más de 30 años en nuestra región, confiamos plenamente que el proceso de destributarización de la misma podrá lograrse cabalmente con el paso de los años. Todo gran camino inicia con un primer paso, y juntos podemos ser agentes de cambio en nuestra apasionante profesión.

\section{Referencias}

Consejo de Normas Internacionales de Contabilidad (2015). Normas Internacionales de Información Financiera para las PYMES. Reino Unido: Editorial Fundación IFRS.

Chávez, Luis A. (2015). Disertación sobre 'NIIF y Tributación: Impuestos Diferidos'. Ecuador: Evento CReCER, organizado por el Banco Mundial, IFAC y el Colegio de Contadores Públicos de Pichincha.

Consejo de Normas Internacionales de Contabilidad (2017). Normas Internacionales de Información Financiera (NIIF). Reino Unido: Editorial Fundación IFRS. 